Article

\title{
Aging, Living Environment, and Sustainability: What Should be Taken into Account?
}

\author{
Indre Grazuleviciute-Vileniske ${ }^{1, *}{ }^{\mathbb{D}}$, Lina Seduikyte ${ }^{1} \mathbb{D}$, Armanda Teixeira-Gomes ${ }^{2,3}$, \\ Ana Mendes ${ }^{2,3}$, Anatolijs Borodinecs ${ }^{4}\left[\right.$ and Deimante Buzinskaite ${ }^{1}$ \\ 1 Faculty of Civil Engineering and Architecture, Kaunas University of Technology, Studentu st. 48, LT-51367 \\ Kaunas, Lithuania; lina.seduikyte@ktu.lt (L.S.); deimante.buzinskaite@ktu.edu (D.B.) \\ 2 EPIUnit-Instituto de Saúde Pública, Universidade do Porto, Rua das Taipas 135, 4050-091 Porto, Portugal; \\ armanda.gomes@insa.min-saude.pt (A.T.-G.); a.sofia.mendes@insa.min-saude.pt (A.M.) \\ 3 Environmental Health Department, National Institute of Health Doutor Ricardo Jorge, Portugal, \\ Rua Alexandre Herculano, 321, 4000-055 Porto, Portugal \\ 4 Riga Technical University, Institute of Heat, Gas and Water technology, Kalku str. 1, LV-1650 Riga, Latvia; \\ Anatolijs.Borodinecs@rtu.lv \\ * Correspondence: indre.grazuleviciute@ktu.lt
}

Received: 29 January 2020; Accepted: 27 February 2020; Published: 1 March 2020

\begin{abstract}
The aging population presents numerous challenges and the design and management of living environments are not an exception. This literature review and analysis brings together topics related to the living environment of the aging population and the concept of sustainability. The article presents the review of the existing design concepts that are applied to planning the environment for the elderly, including (i) design for all, (ii) universal design, and (iii) inclusive design. Furthermore, this review highlights the aspects of sustainability and the peculiarities of the aging population that should be taken into account in the design and management of their living environment. Key points related to sustainable aging are highlighted, and the possibility of complementing the existing design concepts with the concept of biophilic design is proposed in order to strengthen their social, psychological, and ecological aspects.
\end{abstract}

Keywords: designs for the aging population; sustainability; universal design; biophilic design

\section{Introduction}

As people tend to live longer all over the world due to the advances of medicine and other factors, the proportion of the population aged 65 and above will dramatically increase both in developed and developing countries in the forthcoming decades. The literature demonstrates that the rates of mortality are declining the most at ages over 65, and life spans are most rapidly increasing at the ages over 75 years [1-3]. Due to the growth of the above-mentioned age groups in the last decades, the number of elderly and disabled people has grown as well $[1,4]$. Such trends inevitably cause social changes and economic challenges. For example, it is forecasted that the demographic old-age dependency ratio (people aged 65 or above relative to those aged 15-64) will significantly increase in the European Union (EU) in the forthcoming decades: from about 25\% in 2010, it has grown to $29.6 \%$ in 2016 and is predicted to reach $51.2 \%$ in 2070 [2]. The World Health Organization (WHO) defines society as an "aging-society", where people aged 65 years and above constitute $7 \%$ or more of all the population; if this proportion reaches $14 \%$ and above, the society is defined as an "aged-society", and when old-age dependency ratio reaches $20 \%$ and above, the society is considered as a "super-aged-society" [3].

The above-mentioned worldwide trend of aging places new demands on families, communities, and governments, including the healthcare demands, formal and informal care for the elderly, 
housing and other accessible environments [1] "including the type of accommodation, the location of accommodation, availability of necessary supports and care" [3] (p. 140). These demands and challenges are clearly linked with all the main dimensions of sustainability-social, economic, cultural, and environmental—and present enormous opportunities for the design community.

Ageing and the characteristics and needs of the elderly people were already well-researched areas at the end of the 20th century [5]. This research mainly focuses on the needs of elderly people related to their living environment and the links between aging, living environments, and sustainability. The literature review revealed relevant research concerning age-sensitive, age-friendly design, architecture for the elderly [6,7], aging and place [8], aging and housing [9,10], and related design concepts such as universal design [11,12]. For example, S. C. de Souza and A. P. Duarte de Oliveira Post [13] discussed the urgent need of universal design in the hospital environment; M. M. Mustaquim [14] researched the significance of universal design in the everyday life of institutionalized elderly people, and D. E. Crews and S. Zavotka [1] analyzed peculiarities and needs of elderly people and universal design. W. Wu and I. Kaushik [15] used the term "design-for-aging community", thus emphasizing the relevance of design targeted at the challenges that the elderly population is facing. Existing aging concepts, related to both living environments and lifestyles of the elderly population, are relevant for this research as well. For example, E. Iecovich [16] discussed the theoretical aspects and practical implications of the concept of "aging in place". W. M. Jayantha et al. [3], T. Thoma-Lürken et al. [17], and J. Sixsmith et al. [18] analyzed the application of this concept in various situations. J. C. Aceros et al. [19] presented an overview of such aging concepts as "active aging", "successful aging" and analyzed the compatibility of the "aging in place" and "active aging" concepts while using the telecare systems. Sustainable aging attracts the interest of the research community as well. The sustainability here is linked both with lifestyle, institutional issues, and the physical living environment [20]. W. Wu and I. Kaushik [15] introduced such concepts as "sustainable aging" and "sustainable aging design". Connections between design, aesthetics, and health [21] and life satisfaction [6] are highlighted in the analyzed literature as well.

The aim of the article is to present and analyze the design concepts that are applied to designing the sustainable environment for the elderly and the peculiarities of the aging population and to analyze the possibility to complement these concepts with the concept of biophilic design in order to strengthen their social, psychological, and ecological aspects.

\section{Aging and Living Environment}

\subsection{Features and Needs of the Elderly Population}

The elderly population forms a specific social group with complex features and needs that should be analyzed and taken into account by the architects, designers, and planners. In literature and documents, people are usually defined as elders when they reach the age of 65 [22]. Elders are often subdivided into the elderly (65-75 years old), the old (75-90 years old), and the very old (90 and older) [23]. Aging is "a physiological, genetically programmed process accompanied by certain age-related changes in the body" [23] (p. 62); thus it can be noted, that the needs related to the living environment of the elderly people of these groups may differ substantially; moreover, the signs of aging in each individual may appear differently. Numerous approaches to defining the needs and abilities of elderly people currently exist. One of them is the ability/inability of the person to complete the standardized set of activities, which are subdivided into Activities of Daily Living (ADL; bathing, dressing, transferring, feeding, ambulating, and toileting) and Instrumental Activities of Daily Living (IADL; using a telephone, grooming, shopping, housekeeping, and taking medicine properly) [1] (p. 114). This approach can be applied not only to the elderly population but to younger people with various disabilities; however, according to A. F. Newell and P. Gregor, the abilities and needs of the elderly person can be very different if compared to a young disabled person [11]. For example, the general impairment of several functions, such as sight, hearing, dexterity, 
and memory is characteristic to the elderly people instead of one clearly expressed disability $[5,11]$. Moreover, the likelihood of having a major disability increases with age as well [11]. The term "frailty", meaning "multiple alterations in physiological functioning and processes that lead to a decreased ability to complete necessary tasks", is used to indicate the conditions and related needs of elderly people [1] (p. 114). According to D. E. Crews and S. Zavotka [1] (p. 114), the frailty can be described as "decreased mobility, strength, and responsiveness to external and internal stressors, low levels of physical activity and weight loss, along with psychosocial perceptions of health and well-being" and other similar alterations. A. F. Newell and P. Gregor [11] underline the importance to integrate the needs of the informal and/or professional carers designing the environments for the elderly. According to W. M. Jayantha et al. [3], both the physical and psychological needs of the elderly are different from the needs of other age groups. As A. F. Newell and P. Gregor [11] (p. 3) concluded, "the needs and wants of people who are in the autumn of their lives are not necessarily the same as those of younger people". According to V. Shabalin [23] (p. 62), the process of aging is related to both the somatic changes in the body and the transformation of the psyche. The elderly people are often viewed as nervous and depressed [5] and the older age is generally associated with personality changes that are seen as negative. However, according to V. Shabalin [23], elderly people often have advantages over younger people in the creative field. Both physical health and needs (frailty, diversity, and changes in physical needs in the course of aging) and psychological aspects should be considered when designing and adapting the living environment for the elderly population.

\subsection{Design for Elderly Population}

Bearing in mind the above-discussed frailty and more frequent disability of the elderly population, the design approaches providing increased accessibility of the environments should be reviewed. In the 1950s, the standards of "barrier-free" buildings, aimed at making buildings accessible to handicapped soldiers and other people with similar conditions, were developed in the United States [24]. The analyzed literature demonstrates that the idea that the built environment should be accessible to individuals with different capabilities has existed since the 1960s. The adverse effect of inappropriate design on the capabilities of people can be identified as well [4]. This idea, named "environmental docility hypothesis", meaning that "less competent an individual becomes, the more influential the environment is on limiting that person's capabilities", was formulated by M. Powell Lawton [1,25]. According to A. F. Newell and P. Gregor [11] (p. 4), "even able-bodied people can be handicapped by their environment"; meanwhile, adopting the approach that the environment should accommodate to the special needs of the person rather than the person should accommodate to the environment, it is possible to create the opportunities for independence and self-reliance for numerous elderly individuals $[1,16]$.

Numerous design approaches based on this hypothesis were formulated in the subsequent decades. Such approaches usually are not enforceable codes but more a design philosophy; thus allowing architects and designers to respond to the needs of users more creatively and flexibly. When designing the interior and exterior environments in different countries, the existing legal regulations must be met although the objects and environments designed based on these design concepts usually go beyond the compulsory minimum requirements of accessibility [1]. A. F. Newell and P. Gregor [11] and H. Persson et al. [24] identified "universal design", "design for all", "accessible design", "inclusive design", "user-centered design", "user-sensitive inclusive design", and "design for dynamic diversity" approaches.

The solutions of the design for all are usually aimed at social inclusion, diversity, and equality. The main goal of this design concept is that "the products are designed for an all-encompassing customer base and that a product is made to be usable by the widest possible range of people" [24] (p. 507). However, in the case of design for the elderly, the all-encompassing design for all concept attains some criticism. Y. Afacan and C. Erbug [4], A. F. Newell and P. Gregor [11] underlined that the needs of different members of the population, including children, elderly, disabled people, can greatly 
vary; thus the number of guidelines grows in order to benefit all and the likelihood of contradictory guidelines increases. According to H. Persson et al. [24] (p. 508), "what can be barrier-free for one person can be a barrier for someone else".

Universal design concept is based on the idea that the same design can be used by the people of different ages and abilities without special adaptation. It was developed in 1998 by R. Mace. The Center for Universal Design established at North Carolina State University led by R. Mace defines the universal design as the design of products and environments that can be used by all people, to the possible greatest extent, without adapting them or applying specialized design $[1,14,24]$. This definition demonstrates a more flexible and rational approach compared to design for all. Seven major universal design principles are usually distinguished in literature including Equitable Use, Flexibility in Use, Simple, Intuitive Use, Perceptible Information, Tolerance for Error, Low Physical Effort, Size and Space for Approach and Use $[4,12,14]$. Numerous researchers underline the benefits of application of universal design designing the environment for the elderly: according to D. E. Crews and S. Zavotka [1] (p. 116), universal design "benefits people of all ages and abilities"; according to W. M. Jayanthaa et al. [3] (p. 142), "this approach allows providing homes that remain beneficial over time as changes accompany age"; according to S. C. de Souza and E. P. Duarte de Oliveira Post [13] and S. Iwarsson and A. Stahl [26], universal design helps reintegrating the elderly within the society by providing the environment that is safer and designed from the onset as free of barriers and removing any stigma.

The main universal design principles and their possible applications for the aging population are presented in Table 1.

Accessible design and inclusive design concepts are more rational compared to the discussed above. For example, ISO's guide 71 defines the accessible design as "design focused on principles of extending standard design to persons with some type of performance limitation to maximize the number of potential customers who can readily use a product" [24] (p. 509). The inclusive design approach is mainly used in the United Kingdom and is defined in the British Standard on Managing Inclusive Design: "the design of mainstream products and/or services that are accessible to, and usable by, as many people as reasonably possible ... without the need for special adaptation or specialized design" [14] (p. 58). The idea of this approach is similar to the described-above: the design of buildings should be as inclusive as possible for as many people as possible $[14,24]$. The concept of "reasonable" in the definition demonstrates the rationality of the approach.

User-centered design and its extension, the user-sensitive inclusive design concept, are distinguished in this more pragmatic design trend as well. In the case of the elderly people and people with disabilities, the array of the needs of users can be very wide; thus it becomes very difficult to distinguish the representative sample of the user group. In the case of a very wide array of needs and characteristics, it becomes inappropriate to create the design that is accessible by all potential users [11]. According to A. F. Newell and P. Gregor [11] (p. 5), if applying user-centered design in the cases where the people with disabilities are within the group of intended users, the word "centered" should be replaced by "sensitive", because the variety of functional characteristics of the users can be very wide. The aim of the user-sensitive inclusive design is "to provide a pragmatic framework for encouraging designers to take on the challenge of designing for a much wider user group" [11] (p. 5). Meanwhile, the concept of design for dynamic diversity addresses the dynamics of the needs of the elderly population. According to A. F. Newell and P. Gregor [11] (p. 5), design for dynamic diversity acknowledges that in the course of aging, the diversity of people's abilities and needs increases. 
Table 1. The main principles of universal design and the examples of their possible application designing the environment and daily life products for the aging population $[4,12,14]$.

\begin{tabular}{|c|c|}
\hline Principles $[4,14]$ & Solutions [12] \\
\hline $\begin{array}{l}\text { Equitable Use, meaning the design that can be used by } \\
\text { people with different abilities }\end{array}$ & $\begin{array}{c}\text { Automatically opening door } \\
\text { No threshold, zero-step entrances } \\
\text { No threshold walk-in shower } \\
\text { Wider than standard doorways and corridors } \\
\text { Counter tops with varying levels that can be used by standing } \\
\text { and seated users, and people of different heights }\end{array}$ \\
\hline $\begin{array}{c}\text { Flexibility in Use, meaning the design that can meet a } \\
\text { wide array of individual preferences and abilities } \\
\text { without special adaptations }\end{array}$ & $\begin{array}{l}\text { Open floor plan } \\
\begin{array}{l}\text { Various household equipment with the larger buttons far } \\
\text { enough apart that can be pressed accurately }\end{array}\end{array}$ \\
\hline $\begin{array}{l}\text { Simple, Intuitive Use, meaning the design that is easily } \\
\text { understandable and intuitively usable }\end{array}$ & $\begin{array}{l}\text { Various instructions presented in a series of clear illustrations } \\
\text { instead of the use of text }\end{array}$ \\
\hline $\begin{array}{l}\text { Perceptible Information, meaning the design that } \\
\text { effectively communicates the necessary information } \\
\text { to the user }\end{array}$ & $\begin{array}{l}\text { Information provided in contrasting colors, large letters, } \\
\text { audible feedback of appliances }\end{array}$ \\
\hline $\begin{array}{l}\text { Tolerance for Error, defining the design that minimizes } \\
\text { hazards and the adverse consequences of accidental } \\
\text { or unintended actions }\end{array}$ & $\begin{array}{c}\text { The layout of hallways and corridors allowing the user to } \\
\text { return to common areas }\end{array}$ \\
\hline $\begin{array}{c}\text { Low Physical Effort, meaning the design that can be } \\
\text { used efficiently and comfortably and with a } \\
\text { minimum of fatigue }\end{array}$ & $\begin{array}{c}\text { Automatically opening door } \\
\text { Counter tops with varying levels that can be used by standing } \\
\text { and seated users, and people of different heights } \\
\text { Installation of a downstairs bathroom } \\
\text { Planning promoting compactness and walkability, creating } \\
\text { short drives and walking distances in communities }\end{array}$ \\
\hline $\begin{array}{l}\text { Size and Space for Approach and Use, meaning the } \\
\text { design that provides appropriate size and space for } \\
\text { approach, reach, manipulation, and use }\end{array}$ & $\begin{array}{l}\text { Items and appliances mounted on walls that are clearly visible, } \\
\text { easily reachable, and easy for all hand sizes to use } \\
\text { Staircases with consistent treads that are straight and provide a } \\
\text { stopping place in the middle between levels }\end{array}$ \\
\hline
\end{tabular}

The above-distinguished design approaches can be subdivided into two groups: the ones intending to provide the accessibility for the greatest possible diversity of users- "to accommodate all" —and ones that are centered on the particular user or user group (Figure 1.). Bearing in mind that the needs of the elderly change in the course of the aging process and the need to accommodate carers, as well as the need to maintain social inclusion of the elderly, the universal design approach can be viewed as more appropriate. Besides, the economic and environmental aspects should be taken into account, as universally designed housing and spaces do not require re-design as the users age.

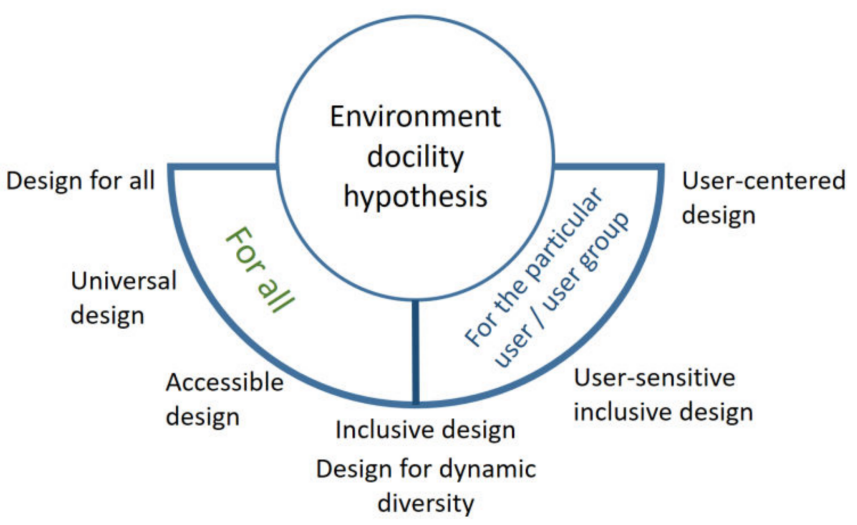

Figure 1. The design approaches that had grown out of the environment docility hypothesis (Lawton (1977)) applicable designing and adapting the environment for the aging population. 


\section{Sustainable Aging and Sustainable Living Environment}

\subsection{The Aspects of Sustainable Aging}

Sustainability is considered the paradigm of the development of contemporary societies. The contemporary notion of sustainability has expanded greatly since its inception in 1987 and currently focuses not only on environmental preservation and economic development. Sociocultural issues and individual well-being are currently the priorities of sustainable development as the human-centered approach; thus, the aging of the population and related challenges must be considered in a sustainability perspective and viewed from the social, economic, and environmental sustainability perspective.

This analysis of the literature revealed numerous concepts targeted at personal well-being and social integration of the elderly population, as sustainability is primarily a human-centered approach. Such concepts as "active aging", "successful aging", "productive aging", "positive aging", "healthy aging" [12,19], and "sustainable aging" [15] were identified. Healthy aging refers "not just to biological and medical aspects of aging; it is a more holistic perspective that includes subjective experiences and meanings, functional definitions emphasizing autonomy, participation and well-being" [18] (p. 1). According to J. C. Aceros et al. [19], the concept "active aging" has become widespread since 2002, when the World Health Organization (WHO) included it into the Active Aging Policy Framework. The main aspects of "active aging" are the possibility to remain healthy and physically active as long as possible and to participate in social, cultural, economic, and spiritual activities [19]. According to C. Cannuscio and J. Block [27], a person's social network, emotional support, and socially significant activities are very important for the mental health of the elderly. Living environment [15] and social integration are very important for achieving the active aging as well, as, according to J. C. Aceros et al. [19], active aging is inseparable from the social interaction with family members, friends, and neighbors. The architectural and urban aspects related to active aging include accessible workplaces, streets, and other public spaces [19].

The economic and environmental aspects of sustainable ageing are strongly related with the challenge of housing for the elderly population as well. As the previous analysis of the dynamics and needs of the elderly population has demonstrated, the number of people who potentially may have special housing needs is constantly increasing and the needs of the elderly people are varying and constantly changing. Developing more residential care services and building more residential institutions to accommodate the growing number of elderly people is not economically and environmentally sustainable. The social aspect is important here as well, as evidence shows that people usually prefer aging in familiar home environment compared to institutional care [3]. The understanding of the importance of the familiar living environment in life of the elderly population and the concerns about sustainability of housing are reflected in the "aging in place" concept. The promotion of this concept started in 1994, when the Organization for Economic Cooperation and Development (OECD) expressed the view that aging people should have the possibility to continue living in their own home environment $[3,19]$. The concept "aging in place" represents "the desire to age in a familiar environment with some dignity and degree of independence" [3] (p. 140). The experience of developed countries demonstrates, that even people in serious medical conditions can age in place. The example of Netherlands can be presented here, as $70 \%$ of approximately 260,000 people with dementia in this country continue living at home supported by informal or professional carers [17]. The "aging in place" concept involves its own design challenges. According to W. M. Jayantha et al. [3] (p. 142), "not only comprehensive community care services, but also appropriate home design" are necessary for the successful aging in place. They recommend the universal design approach for sustainability in housing design for the elderly. Meanwhile, A. Serrano-Jiménez et al. [7] developed the idea that sustainable homes of the elderly could be guaranteed by urban regeneration. The importance of housing design cannot be underestimated in reaching the sustainable aging goals, whether aging-in-place or in purposefully designed accommodations for senior living. According to $\mathrm{H}$. DeGroff and W. McCall [28] (p. 4), the discussions about sustainable architecture and sustainability 
certifications (e.g., LEED) in senior living is an ongoing trend as both the developers and their clients are environmentally cautious; they note that the sustainability label becomes a part of marketing approach as well.

It is evident that the above discussed aging strategies are linked with sustainable development: "active aging" and "healthy aging" are more concentrated on the individual well-being and social inclusion of the elderly; meanwhile, the "aging at home" is linked with economic and environmental sustainability at the same time maintaining the connection to the place and social ties of the elderly (Figure 2). Moreover, all the mentioned concepts are related to the design of the living environment.

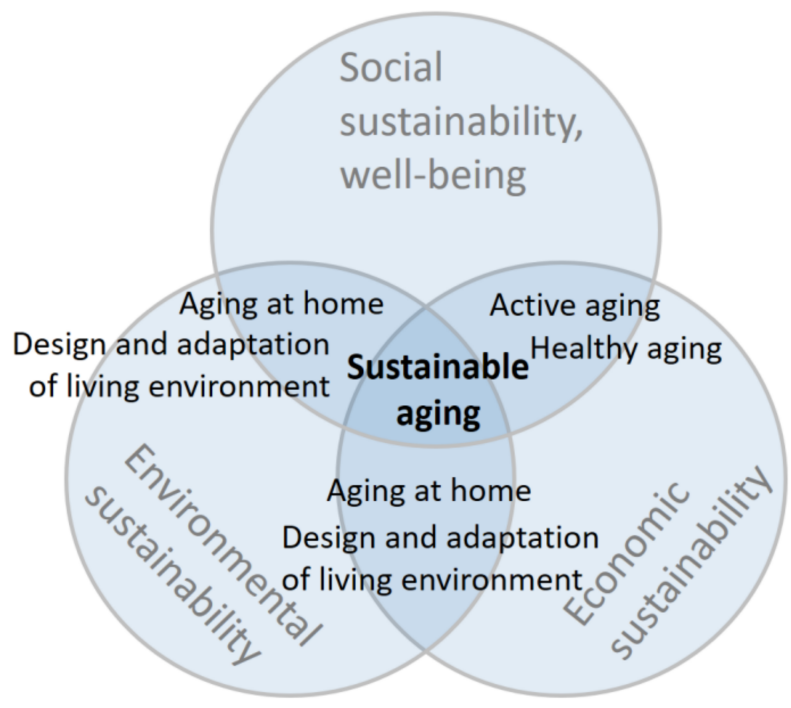

Figure 2. The importance of the living environment for sustainable aging.

\subsection{Biophilic Design as a Part of Sustainable Ageing}

The approaches to housing for elderly people are important from a social, economic, and environmental sustainability point of view, as it was discussed above. However, according to H. DeGroff and W. McCall (2016) [28], while the LEED checklist becomes standard practice in sustainable building design, the social sustainability issue in the living environment of the elderly population is still insufficiently addressed. They proposed the biophilic design concept as a way to address the issue of sustainability in the housing design for the elderly from a social and personal well-being point of view.

The biophilic design approach has received increasing attention in recent years. According to K. Gillis and B. Gatersleben [29], it is the design philosophy that integrates the elements and features of nature designing the human environment. The biophilic design approach is based on the biophilia hypothesis, which was formulated by the Harvard University ecologist and sociologist, E. O. Wilson [30-32]. According to him, biophilia is the innate human tendency to focus positively on the elements and processes of nature [30,32]. H. DeGroff and W. McCall [28] (p. 4) defined it as "human affinity for elements and principles in nature". Meanwhile, the biophilic design approach, which was developed based on E. O. Wilson's hypothesis, is the practice of integrating nature into architecture and design in order to improve health and well-being [32]. According to M. Andrews [33], the practice of biophilic design in urban areas allows for this innate affiliation with nature to be re-established in modern-day society; T. Beatley [34] states that in the environment, which incorporates biophilic design, the natural elements coexist with various elements of the man-made environment. According to $\mathrm{H}$. DeGroff and W. McCall [28] (p. 4), "biophilic design studies the impact of environmental qualities such as light, color, space, shape, air, materials, and vegetation on human physiology and psychology and, by having this knowledge, the architects and designers can mindfully shape the space to improve human 
experiences that occur when interacting with these qualities". The biophilic design promoters $[35,36]$ distinguish 14 patterns of biophilic design that are classified into three categories:

- $\quad$ Nature in the space, meaning the presence and diversity of natural elements and features within the human environment, including vegetation, water bodies, animal species;

- Natural analogs, meaning objects, materials, colors, shapes, patterns, and algorithms that are analogous to natural ones and evoke similar human responses;

- $\quad$ Nature of the space, meaning different solutions of organization of spaces that evoke physiological responses, including prospect, refuge, mystery, risk/peril, characteristic to the experience of the natural environment.

Numerous sources underline the connection of biophilic design and positive physical and psychological health outcomes $[29,32,33,37]$ that are crucial for sustainable aging. The positive impact on psychology should be especially underlined here [23].

Numerous authors underline the biophilic design, biophilic urbanism, and sustainability links [38,39]. Moreover, two internationally acknowledged building rating systems-The Living Building Challenge and the WELL Building Standard—already incorporate biophilic design directly [29]. The examples of the application of biophilic design patterns in home environments and in the environment of care institutions for the elderly are presented in Figure 3.
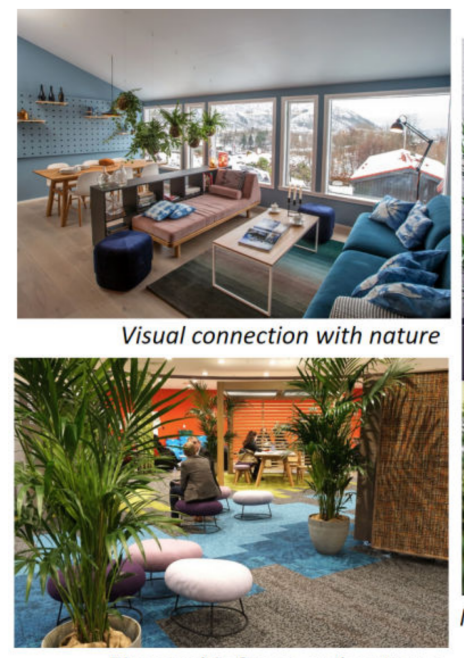

Biomorphic forms and patterns Complexity and order

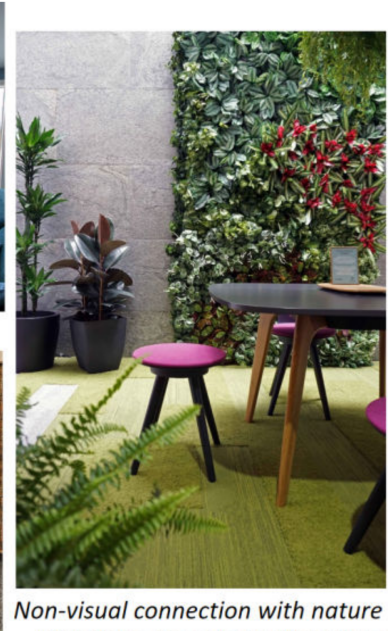
Material connection with nature

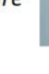

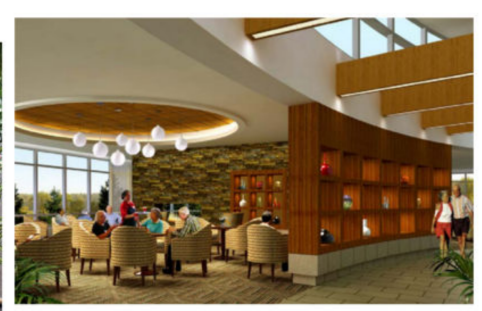

Dynamic and diffuse light

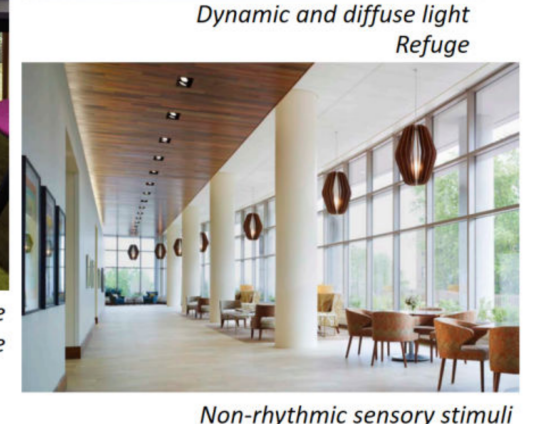

Non-rhythmic sensory stimuli

Figure 3. The examples of the application of biophilic design patterns in home environments and in the environment of care institutions for the elderly $[28,40]$.

H. DeGroff and W. McCall [28] advocate for the application of the biophilic design in the architecture for the elderly and presented a series of case studies of biophilic design in senior living projects. The overview of the projects revealed the designs focused on the experience of the user. The presented design solutions did not appear overly green: no dominant green walls, just moderate interior vegetation, no organic shape design of furniture were observed. The biophilic design solutions for the elderly presented by $\mathrm{H}$. DeGroff and W. McCall [28] look like carefully designed living environments of moderate classical style with lots of natural light and vistas to nature and access to outside natural features, such as gardens with water bodies. The designs concentrate on particular positive aspects of human experience such as exploration and discovery, movement and unpredictability, light, connection to nature, connection to others, spatial experiences. According to them, the biophilic design presents a more human-oriented way towards achieving building sustainability goals [28], as the experience of the resident is the most important in the architecture for senior living [6,28]. 
Biophilic design can be viewed as nature-oriented from the first glance; however, the analysis of both biophilia hypothesis [30-32] and the biophilic design criteria [35,36] reveal that they are primarily oriented towards human well-being and positive human experience generated by the innate affiliation with nature. Biophilic design in this way can be related with the concept of sensory design, where the design solutions are targeted at activating human senses and thus supporting the opportunities to receive information, explore surroundings, and gain positive experiences [41], and biophilic design can be referred to as environmentally responsible sensory design. However, the review of the examples of biophilic design for the elderly presented by H. DeGroff and W. McCall [28] encourage the analysis of possibilities of inclusion of more explicit ecological designs in the interiors, which could be the object of future research.

The analysis of the approaches towards aging and the aging-sustainability links has demonstrated that sustainable aging is strongly related to the living environment. The concept of biophilic design, which can be integrated with universal design solutions, can be applied in designing the living environment for the elderly in order to strengthen the social, psychological, and ecological aspects of sustainable aging.

\section{Conclusions}

The aging trend in societies all around the world has raised social and economic concerns and is one of the relevant issues of sustainability. This literature review reveals the significant attention of researchers of different fields to the challenge of aging: the physical and psychological aspects of aging, aging-related socialization and community issues, the diversity of needs of the elderly, and different aging strategies. The analysis has demonstrated that the trend of aging creates new opportunities to design-related fields although the multiple connections between the needs of the aging population, the existing design approaches, and the sustainability goals are not sufficiently highlighted in the analyzed sources.

The literature review reveals that the needs and preferences of the elderly population are different from those of other age groups or young disabled people. The needs may strongly vary, both within the group identified as the elderly population and the needs of the particular elderly person, and may strongly change in the course of time as aging is more a process than a state. The researchers underline the frailty condition of elderly people and the importance of mental health issues. These issues can be linked with accessibility, social connection and cohesion, aesthetics, and psychological acceptability when designing the living environment for the elderly.

Design for all, universal design, accessible design, inclusive design, user-centered design, user-sensitive inclusive design, and design for dynamic diversity were identified as design approaches that can be applied to designing and adapting the environment for the elderly. The approaches like design for all and universal design encourage creating an environment that accommodates the widest possible diversity of users. The user-centered, user-sensitive approaches focus on particular users or user groups. The focus on the particular user is relevant when designing for the elderly, bearing in mind the diversity of their needs and physical and mental health peculiarities. However, considering the sustainability requirements, including the circular economy and social cohesion aspects, the most adequate and flexible approach is the universal design concept. The universal design concept, encouraging diversity of users and social integration, is favorable for the implementation of healthy aging and active aging concepts. Moreover, universal design is applicable in the aging at home concept: the design solutions of buildings and environment can be from the start adapted to the needs of the elderly, avoiding the necessity of further reconstructions as the users age.

The biophilic design concept based on the innate human emotional affiliation with nature can provide a new perspective in the design and management of the living environment for the elderly population. The application of nature in space, natural analogs, and nature of the space biophilic concepts in designing housing and surrounding environment can, at the same time, strengthen social, psychological, and ecological aspects of sustainable aging. 
Figure 4 demonstrates the main finding of this research: the integration of biophilic design and universal design concepts in shaping the living environment for the aging population and the possible contributions of this integration to sustainable aging. As can be seen in the figure, the universal design approach mainly contributes to economic sustainability and partially to social sustainability, for example, by creating accessibility and resulting social cohesion and the possibility for aging at home, as well as to environmental sustainability by saving the resources; meanwhile, the biophilic design approach contributes to environmental sustainability by raising the ecological awareness and by integrating the ecosystems into the built environment, and to social sustainability and well-being by providing positive user experience, psychological comfort, and health.

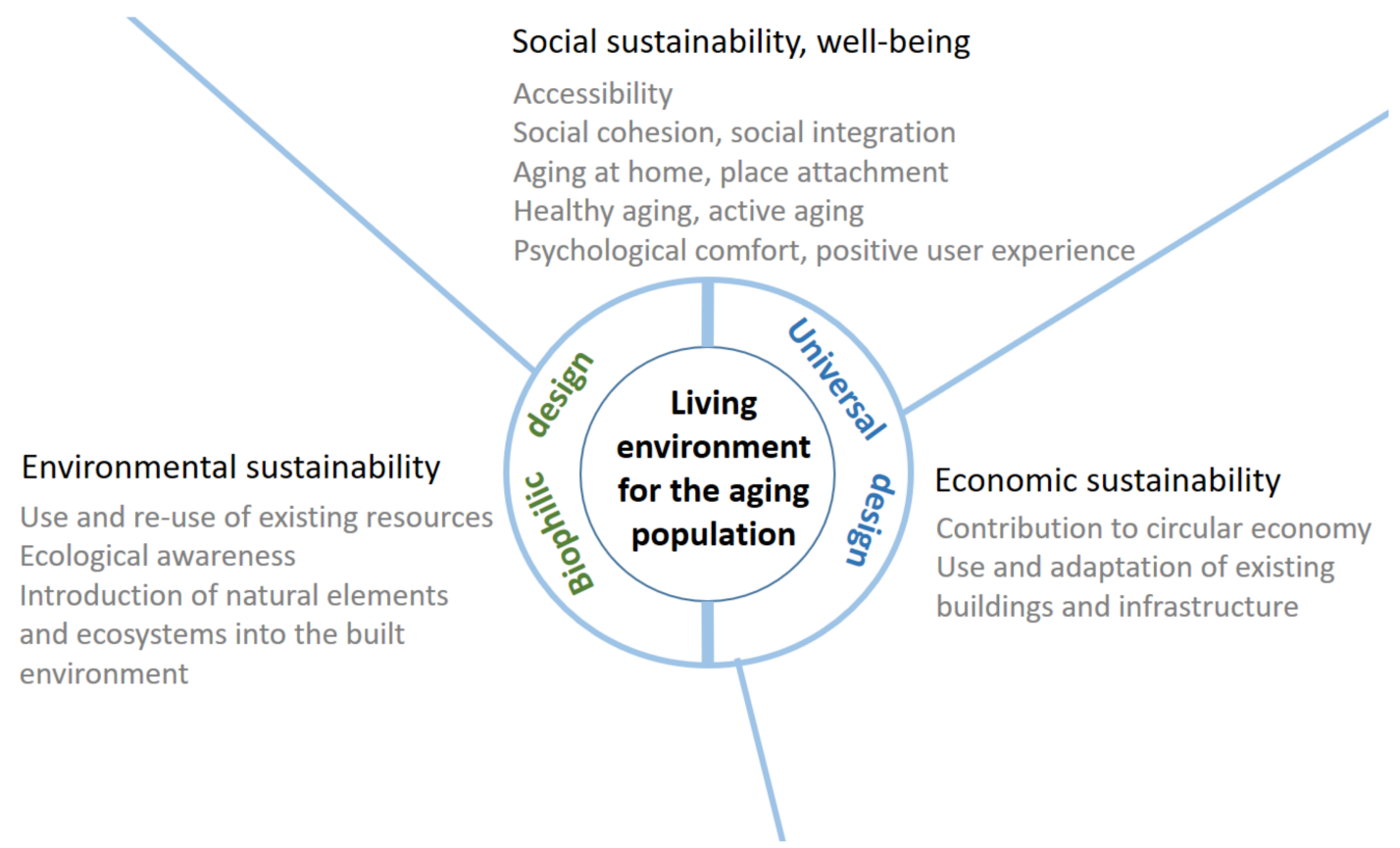

Figure 4. Integration of the universal design and biophilic design concepts for sustainable aging.

Author Contributions: Conceptualization, I.G.-V., L.S., D.B.; methodology I.G.-V., L.S.; resources, I.G.-V., L.S., D.B., A.T.-G., A.M., A.B., D.B.; writing—original draft preparation, I.G.-V., L.S.; writing—review and editing, I.G.-V., L.S., A.T.-G., A.M., A.B.; visualization, I.G.-V.; supervision, I.G.-V., L.S.; project administration, L.S.; funding acquisition, L.S., A.T.-G., A.M. All authors have read and agreed to the published version of the manuscript.

Funding: The work developed by ATG is supported by the Portuguese Foundation for Science and Technology (FCT) under the grant SFRH/BD/121802/2016.

Acknowledgments: This article is based upon work from Sheldon COST Action CA16226 Indoor Living Space Improvement: Smart Habitat for the Elderly, supported by COST. COST (European Cooperation in Science and Technology, ) is a funding agency for research and innovation networks. Our actions help connect research initiatives across Europe and enable scientists to grow their ideas by sharing them with their peers. This boosts their research, career and innovation. COST web link: www.cost.eu.

Conflicts of Interest: The authors declare no conflict of interest.

\section{References}

1. Crews, D.E.; Zavotka, S. Aging, disability, and frailty: Implications for universal design. J. Physiol. Anthropol. 2006, 25, 113-118. [CrossRef] [PubMed]

2. Ageing Report 2018. Underlying Assumptions and Projection Methodologies. European Commission. Available online: https://ec.europa.eu/info/sites/info/files/economy-finance/ip065_en.pdf (accessed on 2 January 2020).

3. Jayantha, W.M.; Qianb, Q.K.; Yia, C.O. Applicability of 'aging in place' in redeveloped public rental housing estates in Hong Kong. Cities 2018, 83, 140-151. [CrossRef] 
4. Afacan, Y.; Erbug, C. An interdisciplinary heuristic evaluation method for universal building design. Appl. Ergon. 2009, 40, 731-744. [CrossRef] [PubMed]

5. Mitchell, D.L.; Goldfarb, A.I. Psychological needs of aged patients at home. Am. J. Public Health 1996, 10, 1716-1721. [CrossRef]

6. Andersson, J.E. Architecture for the silver generation: Exploring the meaning of appropriate space for ageing in a Swedish municipality. Health Place 2011, 17, 572-587. [CrossRef]

7. Serrano-Jiménez, A.; Barrios-Padura, A.; Molina-Huelva, M. Sustainable building renovation for an ageing population: Decision support system through an integral assessment method of architectural interventions. Sustain. Cities Soc. 2018, 39, 144-154. [CrossRef]

8. Severinsen, C.; Breheny, M.; Stephens, C. Ageing in unsuitable places. Hous. Stud. 2016, 31, 714-728. [CrossRef]

9. Boyle, F.; Thomson, C. Housing an ageing population: Implications for managing the social housing stock. In Proceedings of the 29th Annual ARCOM Conference, Reading, UK, 2-4 September 2013; Smith, S.D., Ahiaga-Dagbui, D.D., Eds.; Association of Researchers in Construction Management: Reading, UK, 2013; pp. 1185-1195.

10. Burton, E.J.; Mitchell, L.; Stride, C.B. Good places for ageing in place: Development of objective built environment measures for investigating links with older people's well-being. BMC Public Health 2011, 11, 839. [CrossRef]

11. Newell, A.F.; Gregor, P. Design for older and disabled people-Where do we go from here? Univers. Access Inf. Soc. 2002, 2, 3-7. [CrossRef]

12. Carr, K.; Weir, P.L.; Azar, D.; Azar, N.R. Universal Design: A Step toward Successful Aging. J. Aging Res. 2013, 3, 324624. Available online: https://www.ncbi.nlm.nih.gov/pmc/articles/PMC3570931/ (accessed on 2 January 2020). [CrossRef]

13. De Souza, S.C.; de Oliveira Post, A.P.D. Universal Design: An urgent need. Procedia-Soc. Behav. Sci. 2016, 216, 338-344. [CrossRef]

14. Mustaquim, M.M. A study of universal design in everyday life of elderly adults. Procedia Comput. Sci. 2015, 67, 57-66. [CrossRef]

15. Wu, W.; Kaushik, I. Design for sustainable aging: Improving design communication through building information modelling and game engine integration. Procedia Eng. 2015, 118, 926-933. [CrossRef]

16. Iecovich, E. Aging in place: From theory to practice. Anthropological Notebooks 2014, 20, 21-33.

17. Thoma-Lürken, T.; Bleijlevens, M.H.C.; Lexis, M.A.S.; de Witte, L.P.; Hamers, J.P.H. Facilitating aging in place: A qualitative study of practical problems preventing people with dementia from living at home. Geriatr. Nurs. 2018, 39, 29-38. [CrossRef]

18. Sixsmith, J.; Sixsmith, A.; Malmgren Fänge, A.; Naumann, D.; Kucsera, C.; Tomsone, S.; Haak, M.; Dahlin-Ivanoff, S.; Woolrych, R. Healthy ageing and home: The perspectives of very old people in five European countries. Soc. Sci. Med. 2014, 106, 1-9. [CrossRef]

19. Aceros, J.C.; Pols, J.; Domènech, M. Where is grandma? Home telecare, good aging and the domestication of later life. Technol. Forecast. Soc. Chang. 2015, 93, 102-111. [CrossRef]

20. Senior Living Sustainability Guide. With Seniors in Mind. 2011. Available online: https://www. withseniorsinmind.org (accessed on 13 July 2019).

21. Day, K.; Carreon, D.; Stump, C. The therapeutic design of environments for people with dementia: A review of the empirical research. Gerontol. 2000, 40, 397-416. [CrossRef]

22. Elderly People in Lithuania. Statistics Lithuania. 2014. Available online: https://osp.stat.gov.lt/servicesportlet/pub-edition-file?id=3030 (accessed on 10 June 2019).

23. Shabalin, V. Psychology and psychopathology of the elderly. Int. J. Cult. Ment. Health 2018, 11, 62-67. [CrossRef]

24. Persson, H.; Åhman, H.; Yngling, A.A.; Gulliksen, J. Universal design, inclusive design, accessible design, design for all: Different concepts-One goal? On the concept of accessibility-Historical, methodological and philosophical aspects. Univers. Access Inf. Soc. 2015, 14, 505-526. [CrossRef]

25. Lawton, M.P. The Impact of the environment on aging and behavior. In Handbook of the Psychology of Aging; Warner Schaie, K., Ed.; Van Nostrand Reinhold: New York, NY, USA, 1977; pp. 276-301.

26. Iwarsson, S.; Stahl, A. Accessibility, usability and universal design-Positioning and definition of concepts describing person-environment relationships. Disabil. Rehabil. 2003, 25, 57-66. [CrossRef] [PubMed] 
27. Cannuscio, C.; Block, J. Social capital and successful aging: The role of senior housing. Ann. Intern. Med. 2003, 139, 395-399. [CrossRef]

28. DeGroff, H.; McCall, W. Biophilic Design. An Alternative Perspective for Sustainable Design in Senior Living. Perkins Eastman. 2016. Available online: https://www.perkinseastman.com (accessed on 2 January 2020).

29. Gillis, K.; Gatersleben, B. A review of psychological literature on the health and well-being benefits of biophilic design. Buildings 2015, 5, 948-963. [CrossRef]

30. Wilson, E.O. Biophilia, the Human Bond with Other Species; Harvard University Press: Cambridge, MA, USA, 1984.

31. Wilson, E.O. Biphilia and conservation ethics. In The Biophilia Hypothesis; Kellert, S., Wilson, E.O., Eds.; Shearwater Books: Washington, DC, USA, 1993.

32. Kellert, S.; Calabrese, E. The Practice of Biophilic Design. 2015. Available online: https://www.biophilicdesign.com (accessed on 2 January 2020).

33. Andrews, M. Biophilia: The Secret to Happiness and Well-Being in the City. 2017. Available online: https://marthaaandrews.wixsite.com/design/dissertation (accessed on 2 January 2020).

34. Beatley, T. Biophilic Cities: Integrating Nature into Urban Design and Planning; Island Press: Washington, DC, US, 2010.

35. Browning, W.; Ryan, C.; Clancy, J. 14 Patterns of Biophilic Design; Terrapin Bright Green, LLC: New York, NY, US, 2014.

36. Ryan, C.O.; Browning, W.D.; Clancy, J.O.; Andrews, S.L.; Kallianpurkar, N.B. Biophilic design patterns. Emerging nature-based parameters for health and well-being in the built environment. Int. J. Archit. Res. Archnet-Ijar 2014, 8, 62-76. [CrossRef]

37. Heerwagen, J. Biophilia, health, and well-being. In Restorative Commons: Creating Health and Well-being through Urban Landscapes; Campbell, L., Wiesen, A., Eds.; Gen. Tech Rep. NRS-P-39; U.S. Department of Agriculture, Forest Service, Northern Research Station: Philadelphia, Pennsylvania, 2009; pp. 38-57.

38. Cook, E.A. Biophilic urbanism: Making cities sustainable through ecological design. In Proceedings of the International Conference on Civil, Architecture and Sustainable Development (CASD-2016), London, UK, 1-2 December 2016; pp. 61-64.

39. Sharifi, M.; Sabernejad, J. Investigation of biophilic architecture patterns and prioritizing them in design performance in order to realize sustainable development goals. Eur. Online J. Nat. Soc. Sciences. Spec. Issue Humanit. Soc. Sci. 2016, 5, 335-337.

40. Biophilic Design-Connecting with Nature to Improve Health and Well-Being. 2019. Available online: https://www.oliverheath.com/biophilic-design-connecting-nature-improve-health-well/ (accessed on 13 July 2019).

41. Lupton, E.; Lipps, A. The Senses: Design Beyond Vision; Cooper Hewitt, Smithsonian Design Museum and Princeton Architectural Press: New York, NY, USA, 2018.

(C) 2020 by the authors. Licensee MDPI, Basel, Switzerland. This article is an open access article distributed under the terms and conditions of the Creative Commons Attribution (CC BY) license (http://creativecommons.org/licenses/by/4.0/). 